\title{
An Exploration of Digital Fashion in Pandemic Italy Districts, Designers, and Displays
}

\section{Paolo Franzo ${ }^{1}$}

Università luav di Venezia

paolofranzo@iuav.it

ORCID 0000-0003-1043-5692
Alessandra Vaccari ${ }^{1}$

Università luav di Venezia

avaccari@iuav.it

ORCID 0000-0001-7925-7375

\begin{abstract}
Change is at the heart of the definition of fashion, as many theorists, designers and cultural analysts have shown. This article takes up this perspective to question the role of fashion design in the 21 st century in the relation to cultural, media and technological changes. Adopting a field research approach, the paper analyses the interaction between fashion, designers and digital technologies that are emerging in Italy in order to re-grasp Made in Italy in a futuring perspective. The case studies were selected for their relevance to the digital in terms of design, production, and display. The paper analyses how the pandemic crisis is affecting the Made in Italy, stimulating new ways of designing, understanding, producing, and consuming fashion.
\end{abstract}

\section{Keywords}

Digital technologies

Made in Italy

Fashion futuring 
The research project Fashion Futuring: Emerging Models of Fashion Design in Italy started at Università luav di Venezia in autumn 2019, a few months before the health emergency due to the pandemic ${ }^{2}$.The research aimed to identify, map, and analyse futuring practices (Fry, 2009) in contemporary fashion in Italy, and to contribute to the redefinition of fashion design in its cultural, environmental, educational, and socio-economic implications (Payne, 2019). The initial phase of the research included the elaboration of a methodological framework that compares short and long supply chains on the one hand and, on the other hand, a high degree of technological experimentation, both in the context of large-scale industry and with regard to the phenomenon of makers, and its opposite, for example in the context of Made in Italy manufacturing or small-scale manual dimension (Vaccari \& Vanni, 2020).

The mapping activities made it possible to carry out an initial verification of the model thus outlined. The collection of initial data seemed to confirm an idea of Italian fashion that is closely linked to handmade products, traditional craftsmanship, and the recovery of heritage (Fortis 1998; Colombo, 2009; Micelli, 2011; Bettiol, 2015; Belfanti, 2019; Vacca \& Bertola, 2020). These linkages are the outcome of representations of Italy as an artisan shop, where fashion is made using craft techniques and processes that are stuck in a mythical and idealised time (Segre Reinach, 2010). This image tends to confirm an idea of Italian fashion linked to the relationship between craftsmanship and luxury, preventing the emergence, on the one hand, of the micro-realities that are working in the field of craftsmanship-based social design (Franzo, 2020) and, on the other hand, of the phenomena connected with experimentation with digital technologies. However, the arrival of the lockdown quickly changed the picture, radically questioning the fashion system, the established discourses on Made in Italy, its times, roles, places, the relationship between local and global dimensions, the dynamics of design, process and communication. In the beginning of 2020, Italy was the first European country to launch a lockdown policy, drastically interrupting production activities, exchanges of objects and movements of people. This resulted in the need to quickly identify alternative ways of interpersonal relationships, encouraging the start of experiments with digital technologies and accelerating projects already launched, regarding the way fashion is designed, produced and presented. Italy has thus become an extraordinary test-bed in which to verify the degree of interaction between digital innovation and deep-rooted manufacturing traditions.

The contribution therefore aims to analyse the emerging phenomena in Italy of interaction between fashion, designers and digital technologies, reconceptualising the Made in Italy in a futuring perspective. If, on the one hand, the pandemic has seriously undermined the fashion system, causing store closures, cancelled orders, job losses, and the consequent suffering of workers and suppliers (Black, 2020), on the other hand this crisis has prompted Italian fashion to overcome the narratives of traditional craftsmanship, freeing it from the constraints of an identity based only
The authors shared the contents of the contribution and wrote the conclusions together. Paolo Franzo is responsible for Digital Industrial Districts and Digital Fashion Designers. Alessandra Vaccari is responsible for Fashion Futuring Perspectives and Digital Displays.

$$
2
$$

Fashion Futuring: Emerging Models of Fashion Design in Italy is a research co-conceived by Alessandra Vaccari (Università luav di Venezia) and Ilaria Vanni (University of Technology Sydney). The fi st phase of its implementation at the Università luav di Venezia (2019-2020) was led by Alessandra Vaccari as Principal Investigator and Paolo Franzo as Research Fellow. 
on manufacturing and heritage. Fashion is on the verge of great transformations (Brydges et al., 2020) and many questions come back obsessively to understand what will be its future and how the Italian system will become. In terms of definitions, transformation in fashion is structurally linked to individual and social change, as many theorists, historians and cultural analysts have pointed out (Ceriani \& Grandi, 1995; Pezzini \& Terracciano, 2021). Fashion is "continual changing of styles" (Wilson, 2003, p. 3), but it is also "a structural disposition to accept innovation", as König emphasised (1988, p. 13, in Segre Reinach, 2010). This means that fashion is not just a passive reflection of change, but is itself an "agent of transformation" (Barnard, 2014) capable of acting on a cultural and historical level, as this contribution aims to show.

Through the analysis of a series of experiences, we will question whether fashion can represent a tool of resistance to and redemption from the health emergency, also thanks to digital technologies, supporting desirable - instead of unsustainable futures. The investigation will also allow us to understand the role of fashion designers in this process of transformation, their ability to intervene in this context and to design a sustainable future.

The future, with its multiple implications, is characterising the contemporary fashion debate (Smith et al., 2017; Steele, 2019), which is increasingly aware of being in a time of transition (Irwin, 2015). Taking up Australian design theorist Tony Fry's (2009) reflection on the idea of futuring, design is defined here as a guide for interventions capable of providing new trajectories and redirection practices regarding issues of environmental, economic and social sustainability. As mentioned at the beginning, the concept of futuring has recently been introduced in Italy in the field of fashion, stimulating a reflection on design and production oriented towards sustainable futures and social change.

In the following sections some case studies will be analysed, which have appeared in Italy in recent years or even months, significant for the use of digital technologies in the conception, realisation or presentation of fashion, which can be interpreted as redirection practices. The research was developed through desk analyses and a fieldwork, started in March 2020, characterised by semi-structured individual interviews to the identified cases, to document the processes and the methodologies applied. The interviews, which had been conceived in the previous months in presence, were carried out entirely online, taking advantage of the digital communication platforms that, with the pandemic, have become the most usual tool for work and interaction between people. Thus, as the focus of the research gradually shifted to digital, the tools with which the work was carried out also moved in the same direction.

\section{Digital Industrial Districts}

One of the first phenomena identified by the research is the appearance in Italy of digital projects and websites that are moving beyond the traditional model of the industrial district (Becattini, 1998), which consists of networks of companies geographically connected in limited territories, to link the manufacturing companies in a wide- 
spread way throughout the country through digital platforms (Conti \& Franzo, 2020). Italian Artisan and Up To You Anthology are two examples of digital platforms conceived to connect in an innovative way the different subjects involved in the design and production processes of fashion. Through the analysis of their websites and the interviews conducted with their creators, it is possible to interpret these platforms as digital production districts, through which fashion designers' projects are developed and implemented thanks to a network of manufactures distributed throughout the country. They can be considered actions of "remanufacturing Italy" (Barucco et al., 2020), with the idea that the traditional district system can be reconfigured through technology, enhancing and integrating the functioning components - the individual manufacturing units into new production networks.

The first case study is Italian Artisan ${ }^{3}$, a platform conceived in 2015 by David Clementoni with the aim of connecting Italian manufactures - in particular artisanal — with international designers and brands, overcoming the difficulties of communication and management of supply relationships. The manufactures, currently more than 300 , are distributed along the entire national territory, divided by product specialisations.

The project allows designers to submit a detailed drawing and technical sheet of the garment to be made, receive a quote from the various artisans on the platform, select the best offer and get in touch with the workshop that will produce the article, defining every aspect of the product both in the prototype phase and in final production Fig. 1. During the interview Clementoni says: "Our mission is to make the tradition of Made in Italy accessible. Every day we work to build an ecosystem based on values of humanity that lead to long-term relationships and sustainable growth"4. The concept of ecosystem which Clementoni refers to, highlights the idea of a digital territory in which different organisms interact in a dynamic balance, thus evoking the set-up of production districts. Traditional production processes are thus transformed in favour of custom and commissioned design, thanks to the opportunities offered by digital technologies (Fagnoni, 2018, p. 20).

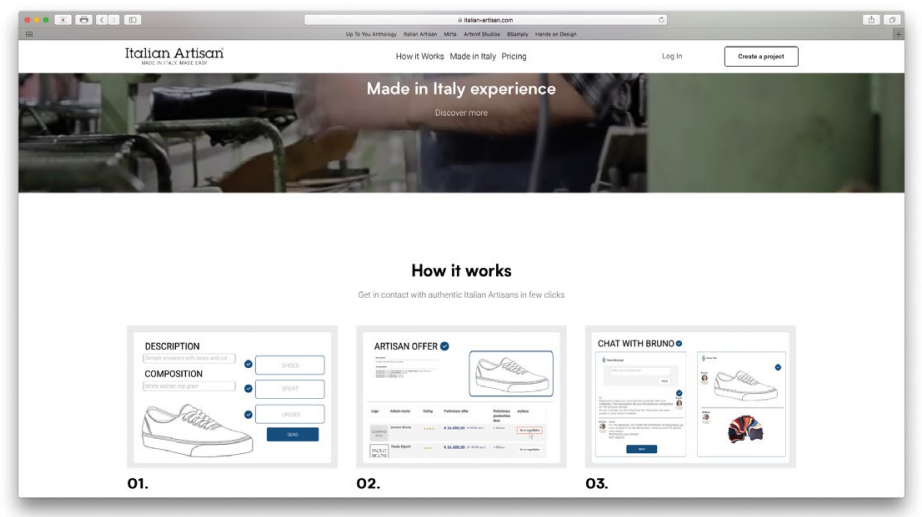

3

www.italian-artisan.com (accessed March 18, 2021).

4

The interview with David Clementoni was conducted by telephone on 20 March 2020.
Fig. 1

Italian Artisan, Made in Italy, Made Easy, 2020. Retrieved from: italian-artisan.com 
The second case study is Up To You Anthology ${ }^{5}$, an online bag design platform founded in December 2019 by Nicolò Gavazzi and which describes itself as a democratic showcase.

The website already highlights its dual function from the homepage. Selecting Shop your bag takes you to a traditional e-commerce, where you can buy bags designed by international designers exclusively for the platform. The innovative aspect is found by accessing the Design your bag section. Anyone can submit their creative idea, sending drawings and details of the bag they want to produce; if the Up To You Anthology team deems the proposal suitable, the proposer is assisted by a consultant for the development of the product and the creation of the prototype by the artisans involved in the project Fig. 2. The next stage involves the production of still-life photos of the prototype to be used for e-commerce and pre-order.

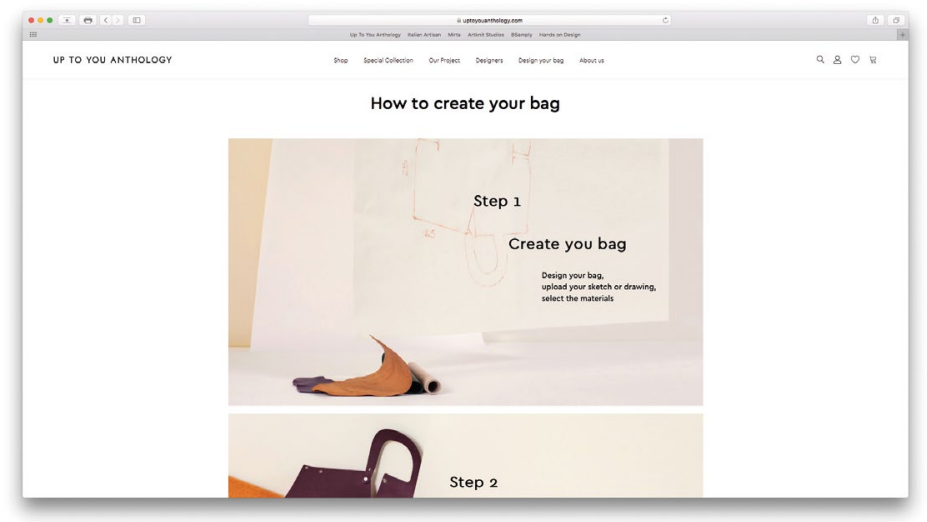

This project seems to implement the idea of widespread design, practised by everyone without any particular knowledge or skills, as defined by Ezio Manzini (2015). Everyone can have access even indirectly - to the Made in Italy production system, which is traditionally more closed to external incursions. In addition to new perspectives for fashion production in Italy, this second case study brought out signs of change in the role of the designer in the digital landscape, suggesting the possibility of a designer who is no longer an individual protagonist of the creative and productive process, but one of the actors involved, in an open perspective (Romano, 2015) of horizontal collaboration between designers, entrepreneurs, artisans, sellers, customers.

\section{Digital Fashion Designers}

The exploration of new approaches to digital and open source design is at the heart of Eugenia Morpurgo's work ${ }^{6}$. As the Italian designer stated during the interview ${ }^{7}$, through her design work she wants to reflect on the impact of production processes on society, not only by prototyping alternative products, but also by suggesting com (accessed March 18, 2021).

www.eumo.it (accessed March 16, 2021).

\section{7}

The interview with Eugenia Morpurgo was conducted online on 12 June 2020.

Fig. 2 Up To You Anthology, How to Create Your Bag, 2020. Retrieved from: uptoyouanthology.com 
alternative scenarios. Morpurgo has decided to cultivate her own autonomy from the demands of the fashion system and its market, positioning herself in a parallel dimension where, for example, the traditional values of industrial secrecy and know-how give way to experimentation in an open and participatory way (Franzo \& Vaccari, 2020). Examples of the latter are her projects Don't run - beta and AnOtherShoe, which are the manifesto of a new model of shoe production based on shared knowledge and local manufacturing, through small-scale, on-demand digital fabrication; the shoe was digitally designed by Morpurgo and the technical drawings made public so that anyone can use them on laser-cut and 3D printers to make the components. The shoe assembly process is reversible and handmade, eliminating the use of seams and adhesives, allowing the consumer to make the shoe himself and repair it if necessary Fig. 3. This parallel system makes it possible to transfer shoe production from delocalised factories to local workshops. It therefore makes the fashion production process more transparent, giving people the knowledge of how fashion is made. As Morpurgo explains, "the consumer / spectator / citizen is transformed into collaborator / student / teacher". Morpurgo used the machines already present in the Fablabs, but she also modified them and designed new ones, with open source software and standard components.

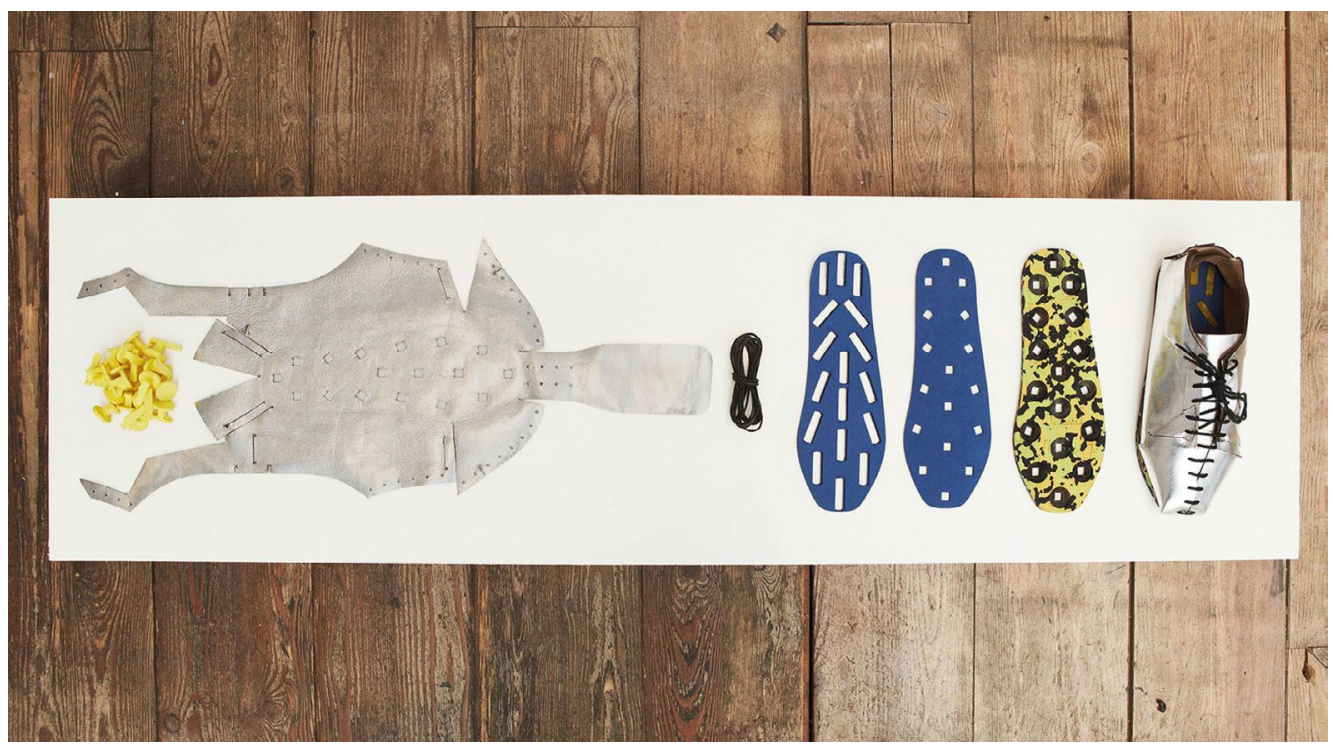

If Morpurgo has found in digital manufacturing the tool to experiment and develop an open source approach in the production of physical objects, a rapidly expanding phenomenon is the design of digital fashion, where the outcome of the design is entirely dematerialised. A case study in Italy is IL $3 X^{8}$, a start-up founded in January 2020 with the aim of designing and selling digital garments that can be worn in social networks and live experiences, thanks to the use of facial recognition and body tracking, anchoring a digitally designed object to physical points on the body. The brand operates on two 
different fronts: both by creating wearable 3D digital objects, and by providing real objects with augmented reality, with digital animations that are activated when a pre-defined object is recognised. The digital garments are presented on the website as Designed in Italy, rather than Made in Italy, underlining the deliberate detachment from the manufacturing identity of Italian fashion, while maintaining a reference to the equally classic concept of Italian design.

The interview with Erika Lamperti ${ }^{9}$, founder of IL3X, reveals that the pandemic crisis has led to a rapid development of digital experimentation in fashion in Italy. The development of the IL3X project, imagined at the end of 2019 , has undergone a strong acceleration in the early months of 2020 to respond to the changes in people's habits generated by the lockdown: from 2020 it no longer seems necessary to move from home to work or act socially, and collaborations with physically distant professionals no longer seem impossible. In this context, therefore, the possibility of socialising in digital spaces offers much more ground for companies such as IL3X, which design garments to be used in the context of mixed reality (Vaccari et al., 2020). Digital reality thus seems to increase the degree of creative freedom of fashion designers, even in Italy, freeing them from the constraints of material production: fabric yield, tailoring techniques, fit and cost. This approach not only leads to a reduction in time and costs, but also allows them to experiment with a greater number of creative ideas. The scenario imagined by many designers such as Lamperti includes the development of entirely digital collections, digital wardrobes of clothes $^{10}$, that allow for a more intense fashion experience than the physical one, with garments that come alive, transform, include sound experiences and narrate themselves.

\section{Digital Displays}

A third area of experimentation with digital technologies identified by the research concerns the way fashion is presented. Since the beginning of 2020 , several experiences have emerged in Italy that question how fashion can be shown and sold outside of physical reality.

One case study is Sense-Immaterial Reality ${ }^{11}$, a company founded in 2018 to develop multisensory shared experiences of immaterial reality in the textile sector, one of the most important areas of the Italian fashion system. The Sense Fabric mobile application allows users to simulate the physical behaviour of fabrics, observing their movement by touching the device, blowing on the screen or moving it. These fabrics can be visualised on a digital outfit which, thanks to the augmented reality, is perceived as part of the physical environment. As stated by Silvia Valeria Rinaldi, Chief Magic Officer of Sense, during the interview ${ }^{12}$, "today the magic wand is our mobile phone, transformed into a real futuristic tool [...]. The illusion is to bring the real sensations of the products wherever you are". In this sense, technology makes it possible to create immaterial objects to be experienced in physical life. Rinaldi adds that mobile applications like the one developed by Sense have made it possible to bring the showroom to the customer's home. The

\section{9}

The interview with Erika Lamperti was conducted online on 2 September 2020.

10

Lamperti has published the beta version of

Ardrobe project, which alludes to the idea of a wardrobe in AR (Augmented Reality). wwww. ardrobe.com (accessed March 22, 2021).

11

wwwv.sense-immaterial reality.com (accessed March 18, 2021).

12

The interview with Silvia Valeria Rinaldi was conducted online on 2 September 2020. 
creation of immaterial catalogues thus allows textile companies to present their collections to designers and manufacturers remotely, reducing waste, time, rehearsals and travels. This opportunity proved to be extremely promising during the lockdown, which entailed the cancellation of the major textile fairs.

Another experience that highlights the changes taking place in fashion distribution in Italy is Sunnei brand, founded in Milan in 2014 by Loris Messina and Simone Rizzo ${ }^{13}$. The Sunnei Canvas project, launched in July 2020, consisted of a platform in which digital avatars wore some of the brand's most iconic unisex garments, including accessories and shoes (Blanks, 2020). The retailers were guided through this experience by the avatars themselves, with the possibility of customising the outfit by choosing colour, fabric and stitching.

The Sunnei Canvas project shows how digital is transforming roles in fashion, by turning the seller into the co-designer of the collection, thus participating in the creative choices that are translated from the digital dimension into the physical one. The Sunnei Canvas project was further developed in January 2021 into a videogame Fig. 4, which has become a rapidly expanding phenomenon in the current rush to the digital transformation of fashion (Mascio, 2012).

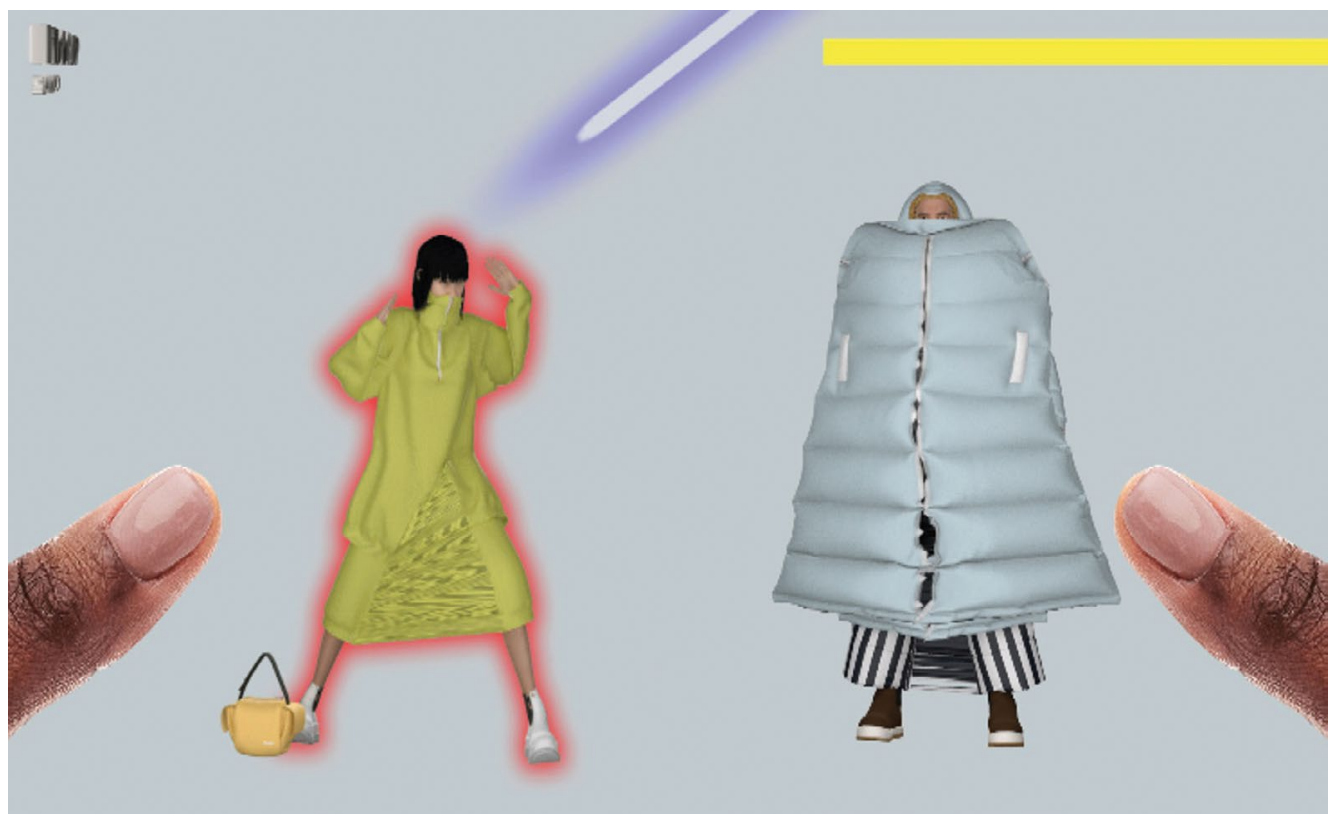

Fig. 4

Sunnei, Sunnei Canvas, 2021. Retrieved from: sunnei.it 


\section{Conclusions}

The Covid-19 pandemic has strongly affected the Italian fashion system as a whole. The awareness that it is in a transitional phase leads to a reconsideration of previous logics. The concept of Made in Italy, as highlighted in this article, must inevitably be redefined, because of the ongoing dynamics between design and manufacturing, and between histories and cultures of fashion.

The analysed case studies made it possible to understand how the pandemic emergency, in addition to causing a dramatic social, health, and economic crisis, has also brought to light how fashion is increasingly experimenting with digital technologies in Italy. As a consequence, emerging fashion brands have distanced themselves from the stereotype of Italian fashion as glamour, luxury and craftsmanship. It has also renewed the trust between fashion and the modernism-rooted concept of change, strengthening the relationships with technologies from the one hand and, on the other hand, showing the power of fashion as an agent of transformation.

\section{Paolo Franzo}

Paolo Franzo, Ph.D., is

Research Fellow at the Università luav di Venezia. His research interests include environmental and social sustainability in fashion design and production; the places of Made in Italy and the new configurations of industrial districts; the education of fashion designers and the role of the portfolio in the construction of professional identity.

Alessandra Vaccari Alessandra Vaccari's research and teaching are in the area of fashion history and theory. With a background in contemporary art history, she works at the interface between visual studies and design history. She is Associate Professor at the Università luav di Venezia. Her recent books include Time in Fashion (Bloomsbury, 2020) and Remanufacturing Italy (Mimesis, 2020). 
Barnard, M. (2014). Fashion Theory: An Introduction. Routledge.

Barucco, M. A., Bulegato, F., \& Vaccari, A. (Eds.). (2020). Remanufacturing Italy. L'Italia nell'epoca della postproduzione. Mimesis-DCP luav.

Becattini G. (1998). Distretti industriali e made in Italy. Le basi socioculturali del nostro sviluppo economico. Bollati Boringhieri.

Belfanti, C. M. (2019). Storia culturale del Made in Italy. II Mulino.

Bettiol, M. (2015). Raccontare il Made in Italy. Un nuovo legame tra cultura e manifattura. Marsilio.

Black, S. (2020). Fashion in a Time of Crisis. Fashion Practice, 12(3), 327-330.

Blanks, T. (2020, July 16). How Sunnei Bucked the Fashion System. Business of Fashion. www.businessoffashion.com/articles/ tims-take/is-sunnei-the-future-of-milan-fashion

Brydges, T., Retamal, M., \& Hanlon, M. (2020). Will COVID-19 support the transition to a more sustainable fashion industry? Sustainability: Science, Practice and Policy, 16(1), 298-308.

Ceriani, G., \& Grandi, R. (Eds.). (1995). Moda Regole e Rappresentazioni. Franco Angeli.
Colombo, P. (2009). Mestieri d'arte e Made in Italy. Marsilio.

Conti, G. M., \& Franzo, P. (2020). Distretti produttivi virtuali. La transizione del Made in Italy nella moda. In M. A. Barucco, F. Bulegato, \& A. Vaccari (Eds.), Remanufacturing Italy. II Made in Italy nell'epoca della postproduzione (pp. 124-143). Mimesis-DCP luav.

Fagnoni, R. (2018). Da ex a next. Design e territorio: una relazione circolare basata sulle tracce. MD Journal, 5, 16-27.

Fortis, M. (1998). // made in Italy. II Mulino.

Franzo, P. (2020). Talking Hands. Ripensare il Made in Italy nella prospettiva del fashion futuring. $M D$ Journal, 9, 186-199.

Franzo, P., \& Vaccari, A. (2020). Futuri sostenibili. Un'indagine sul ruolo dei fashion designer emergenti del XXI secolo. AND Rivista di architetture, città e architetti, 37, 56-63.

Fry, T. (2009). Design

Futuring: Sustainability, Ethics and New Practice. Bloomsbury.

König, R. (1988). Umanità in passerella. La moda nel processo di civilizzazione. Longanesi.
Irwin, T. (2015). Transition Design: A Proposal for a New Area of Design Practice, Study, and Research. Design and Culture, 7(2), 229-246.

Manzini, E. (2015). Design, When Everybody Designs: An Introduction to Design for Social Innovation. The MIT press.

Mascio, A. (2012). Fashion Games. FrancoAngeli.

Micelli, S. (2011). Futuro artigiano: l'innovazione nelle mani degli italiani. Marsilio.

Payne, A. (2019). Fashion Futuring in the Anthropocene: Sustainable Fashion as "Taming" and "Rewilding". Fashion Theory. The Journal of Dress, Body \& Culture, 23(1), 5-23.

Pezzini, I., \& Terracciano, B. (Eds.). (2021). La moda fra senso e cambiamento. Teorie, oggetti, spazi. Meltemi.

Romano, Z. (2015). Openwear Collaborative Clothing. In A. Fuad-Luke, A.-L. Hirscher, \& K. Moebus (Eds.), Agents of Alternatives: Re-design our Realities (pp. 220-228). Agents of Alternatives.

Segre Reinach, S. (2010). La moda: un'introduzione. Laterza.
Smith, P., Baille, J., \& McHattie, L.-S. (2017). Sustainable Design Futures: An open design vision for the circular economy in fashion and textiles. The Design Journal, 20(1), 938-947.

Steele, V. (2019). Fashion Futures. In A. Geczy, \& V. Karaminas (Eds.), The End of Fashion: Clothing and Dress in the Age of Globalization (pp. 5-18). Bloomsbury.

Vacca, F., \& Bertola, P. (2020). Eccellenza italiana: artefatti ad alto contenuto culturale. MD Journal, 9 , 146-153.

Vaccari, A., Franzo, P., \& Tonucci, G. (2020). Mise en abyme. L'esperienza espansa della moda nell'età della mixed reality. ZoneModa Journal, 10(2), 75-89.

Vaccari, A., \& Vanni, I. (2020). Fashion Futuring: un modello di produzione sostenibile nella moda. In M. A. Barucco, F. Bulegato, \& A. Vaccari (Eds.). Remanufacturing Italy. L'Italia nell'epoca della postproduzione (pp. 48-61). Mimesis-DCP luav.

Wilson, E. (2003). Adorned in Dreams: Fashion and Modernity. I.B. Tauris. 